\title{
Resultado das Vivências Realizadas no Processo de Ambientação e Imersão do Programa de Residência Pedagógica na Escola Campo
}

\author{
Maria Ednalva da Silva Pereira ${ }^{1}$; Aurelania Maria de Carvalho Menezes ${ }^{2}$; \\ Maria das Graças Bento Gonçalves de Oliveira ${ }^{3}$
}

\begin{abstract}
Resumo: Este artigo vem abordar as etapas observadas e vivenciadas do PRP - Programa de Residência Pedagógica, através do olhar e das práticas do residente, demonstrando aspectos positivos e negativos sobre o processo de ensino aprendizagem. Pretende-se mostrar a estrutura física e administrativa que compõe a escola campo Dom Malan no município de Salgueiro-PE, refletindo sobre algumas dificuldades encontradas desde o período da ambientação, até à fase de Imersão. A participação do residente nessa trajetória torna-se imprescindível, estabelecendo interação social, habilidades e sobretudo colaborando para o crescimento do acadêmico através da união entre o escrito e o vivido. $\mathrm{O}$ trabalho vem discutir a respeito de alguns temas importantes que devem ser revistos e considerados tais como; a prática da Educação Física nesse espaço de forma constante para melhorar o desempenho desses alunos, incentivo ao corpo docente para aperfeiçoamento de suas ações, além de melhoramento no contexto da inclusão de alunos com necessidades especiais. Fez-se necessário o uso de várias pesquisas bibliográficas através de nomes como: Pimenta e Lima (2004), Kunz, (2001), e outras fontes. Este trabalho tem natureza qualitativa, quantitativa, descritiva, aplicada, levantamento e estudo de caso, para compreender alguns fatores existentes e ausentes no âmbito educacional. Alguns mediadores e residentes atuantes dentro desse sistema foram convidados a participarem desse trabalho através de questionamentos onde puderam fornecer opiniões e sugestões relativas ao processo inclusivo em cada setor, corroborando de maneira positiva.
\end{abstract}

Palavras-Chave: Programa de Residência Pedagógica, Imersão, Ambientação, Aperfeiçoamento, Práticas.

\section{Result of Experiences Carried out in the Environmental Process and Immersion of the Pedagogical Residence Program at Campo School}

\begin{abstract}
This article addresses the observed and lived stages of the PRP - Pedagogical Residency Program, through the resident's look and practices, demonstrating positive and negative aspects about the teaching-learning process. It is intended to show the physical and administrative structure that composes the field school Dom Malan in the municipality of Salgueiro-PE, reflecting on some difficulties encountered from the period of the setting, until the Immersion phase. The resident's participation in this trajectory becomes essential, establishing social interaction, skills and above all contributing to the academic growth through the union between the written and the lived. The paper discusses some important topics that should be reviewed and considered such as; the practice of Physical Education in this space constantly to improve the performance of these students, encouraging the faculty to improve their actions, and improvement in the context of the inclusion of students with special needs. It was necessary to use various bibliographic searches through names such as: Pimenta and Lima (2004), Kunz (2001), and other sources. This work is qualitative and quantitative, descriptive, applied survey and case study to understand some existing and absent factors in the educational field. Some mediators and residents operating within this system were invited to participate in this work through questions where they could provide opinions and suggestions regarding the inclusive process in each sector, corroborating positively.
\end{abstract}

Keywords: Pedagogical Residency Program, Immersion, Environment, Improvement, Practices.

\footnotetext{
${ }^{1}$ Graduanda em Pedagogia, Faculdade de Ciências Humanas do Sertão Central FACHUSC. neinha.gatona10@ gmail.com;

${ }^{2}$ Pedagoga. Faculdade de Ciências Humanas do Sertão Central FACHUSC. lelamenezesluiza@ yahoo.com.br;

${ }_{3}^{3}$ Mestre, Universidade Católica de Pernambuco. professoragracabento@ hotmail.com.
} 


\section{Introdução}

O presente trabalho vem relatar as experiências do residente do PRP - Programa de Residência Pedagógica da CAPES - Coordenação de Aperfeiçoamento de Pessoal de Nível Superior, mostrando os resultados coletados das vivências e pesquisas realizadas nesse ambiente. Sabemos da relevância da educação na vida de qualquer indivíduo. Ao ser introduzido nesses espaços os residentes passam por experiências que acarretam muita bagagem.

Ressaltamos a escassez de exercícios físicos, problemas direcionados à parte estrutural e administrativa. Queremos destacar a contribuição desses residentes com os projetos de intervenção, como também evidenciar algumas problemáticas levantadas a respeito dos desafios enfrentados pela docência na tentativa de incluir os estudantes com necessidades especiais, em um ambiente que não se encontra totalmente preparado. Houve algumas anotações no caderno etnográfico sobre horário de entrada e saída, estrutura geográfica e física do grêmio, registro de pontos dos funcionários, quantos colaboradores atuam na instituição, além das informações relacionadas ao pedagógico. Esse ponto foi importante para compreendermos melhor o funcionamento da escola.

É percebido que não somente o ambiente deve passar por reforma, mas todos que fazem parte dessa associação tentando especializar-se para melhor atender os discentes de forma igualitária. Todo trabalho baseou-se em observações, registros, palestras, questionários, participações em reuniões e outros procedimentos metodológicos afim de descobrir e discutir temáticas que pudessem contribuir para o alargamento estudantil. Foi evidente que durante as abordagens feitas aos alunos e funcionários, detectamos algumas lacunas que precisam ser preenchidas com urgência. O Programa Residência Pedagógica trouxe consigo um leque de possibilidades, complementando a formação do licenciando. O nosso país em sua história sempre enfrentou desafios dentro da educação, contudo, esses desafios são necessários para chegar a uma educação de qualidade. A presença desses universitários contribui sem dúvidas para avanços na educação, iniciativas como essas vem engrandecer a todos, principalmente a nossa cidade ao receber pela primeira vez esse tipo de auxílio.

920 Id on Line Rev. Mult. Psic. V.13, N. 48 p. 919-933, Dezembro/2019 - ISSN 1981-1179 Edição eletrônica em http://idonline.emnuvens.com.br/id 


\section{PRP: relatos das observações e vivências da Residência Pedagógica}

O Programa de Residência Pedagógica - PRP, foi oferecido pela CAPES em parceria com a Faculdade de Ciências Humanas do Sertão Central, visa inserir graduandos nas instituições de ensino da rede pública de educação, no Ensino Básico. Para chegar à residência foi necessário que os candidatos cumprissem algumas exigências como, a elaboração de uma carta motivadora onde expressaria o interesse e disponibilidade para atuação, além do cadastro do curriculum na Plataforma Freire, contemplando os graduandos do 6 período das licenciaturas em Pedagogia e Ciências Biológicas. Os participantes passaram por seleções no processo classificatório, os contemplados receberiam uma bolsa para auxiliar durante o percurso. Vale lembrar que antes da chegada dos residentes nas determinadas escolas, os coordenadores fizeram reuniões com os líderes de cada órgão para explicar o passo a passo do programa. No primeiro encontro tivemos a oportunidade de conhecer a secretária, que foi direcionada a receber e supervisionar os residentes, dando acesso direto a conhecer toda a estrutura física do local, oferecendo a documentação e informações necessária para as pesquisas.

Os Preceptores do PRP - são professores da Educação Básica que acompanharam os residentes na escola-campo- foram divididos por núcleo - Pedagogia e Ciências Biológicas para organização e acompanhamento, orientando, tirando dúvidas e controlando frequência, garantindo o contato físico de cada residente dia após dia nas escolas. Cada etapa foi monitorada com: registros mensais de horas, planos de atividades, reuniões com a coordenação afim de discutir e acompanhar todo o sistema.

Desenvolvemos algumas tarefas na secretaria como: preenchimentos de notas no diário, fichas individuais, confecções e recortes de cartazes para ornamentação, além de observar como fazer histórico e matrículas, aproveitamos também esse espaço para realização de alguns projetos da faculdade de outras disciplinas como: Prática de Ensino, Educação Física e Educação do Campo. Constatamos o real envolvimento da instituição enfatizando e discutindo sobre tema como Consciência Negra, violência e indisciplina. A escola pretende levar adiante outros assuntos, pois considera que vários problemas podem ser resolvidos e esclarecidos através de palestras, reuniões e círculo de cultura, conscientizando e ensinando esses alunos a respeitarem tanto o patrimônio público quanto os indivíduos.

921 Id on Line Rev. Mult. Psic. V.13, N. 48 p. 919-933, Dezembro/2019 - ISSN 1981-1179 Edição eletrônica em http://idonline.emnuvens.com.br/id 
Diante disso podemos afirmar que o trabalho da gestão, não se limita a resolução de problemas logístico, pedagógico ou financeiro, mas também, perceber a necessidade da escola de maneira geral, incluindo projetos e medidas que alcance toda a comunidade no intuito de melhores resultados. A gestão deve abrir espaço para o outro, acreditar em seus companheiros, e ser exemplo para os demais que trabalham no setor com o pensamento voltado para ampliação de todo o grupo: escola, aluno e comunidade.

O PPP - Projeto Político Pedagógico estava passando por algumas transformações, no entanto não foi possível fazer uma análise desse importante documento, onde sabemos que nele existem informações que regem o andamento do setor, mas durante as pesquisas feitas nesse trajeto, podemos considerar como gestão compartilhada e participativa. Essa escola é composta pelo gestor, gestor adjunto, coordenadora pedagógica, secretária e alguns agentes administrativos que ajudam a cuidar de todos os procedimentos institucional. A escola conta ainda com 59 funcionários. No arquivo encontra se tudo esquematizado em pastas enumeradas por ordem alfabética, todos os dados e informações referente ao ambiente são preenchidos e atualizados, alunos e funcionários comparecem sempre de uniformes no estabelecimento cumprindo os horários estabelecidos de forma integral.

\section{Descrição física escolar}

A escola fica localizada na cidade de Salgueiro-PE e foi fundada em 25 de abril de 1956. É uma escola de referência de Ensino Fundamental, situada à rua Carlos Soares de Brito S/N. A escola possui biblioteca, sala de professores, secretaria, diretoria, auditório, sala de vídeo, sala de AEE - Atendimento Educacional Especializado e quatro banheiro espalhados no âmbito estudantil. Conta ainda com 13 (treze) salas de aula, refeitório e alguns corredores. 17 (dezessete) turmas, abrigando quase 600 alunos do Ensino Fundamental I e II. Apesar do local ser espaçoso, faltou planejamento para construção da obra, alguns setores são gigantes, enquanto outros são pequenos como o refeitório, mas algumas barracas foram improvisadas para abrigar as turmas na hora das refeições. Vale lembrar que outros setores também precisam de mudanças para atender melhor sua equipe, tais como: banheiros, quadra de esporte que necessita urgentemente de cobertura e reforma, a mesma encontra-se em estado precário, e os alunos com deficiência quase não tem acesso, prejudicando ainda mais no desempenho. 
Foi observado que os funcionários são criativos, pois todo o ambiente é ornamentado de acordo com as datas comemorativas para receber alunos, pais e colaboradores. É nítido que há uma preocupação relacionada a preservação e reciclagem, no intuito de manter limpo e organizado o ambiente. Os dados coletados nos primeiros momentos serviram de base para o fechamento das atividades do período de Ambientação. Foi proposto aos residentes a criação de um resumo expandido, mas antes fomos contemplados com dois minicursos, oratória e Produção de Textos para ajudar na construção e apresentação do trabalho. No mês de janeiro, período de férias, os residentes continuaram atuando nas secretarias das escolas para garantir a frequência e coleta dos dados.

\section{Nova Etapa: Imersão e Regência}

A fase de imersão ocorreu no período de 320 horas distribuídos entre regência, seguidos dos resultados e divulgações. Nesse período percebemos que a escola aproveitou alguns residentes para ajudar os alunos que se encontravam com problemas de aprendizagem, foram intercalados para darem aulas extras em horários diferenciados como aula de reforço. Os residentes que foram indicados para a escola, passaram por algumas mudanças, pois a fase de observação seria finalizada, dando início a um outro ciclo. Nesta etapa fomos inseridos dentro das salas de aula, juntos aos professores, a disposição, tanto da escola quanto dos docentes. Nesse momento, tivemos a oportunidade de conhecer ainda mais o campo atuante e intensificar as pesquisas.

Para Pimenta e Lima (2004):

\footnotetext{
O estudo realizado na passagem dos estagiários pelas instituições, departamentos e secretarias representantes do sistema de ensino constituirá um transitar entre o escrito e o vivido e terá por objetivo a busca de compreensão das influências desses organismos no trabalho cotidiano nas escolas". (PIMENTA, LIMA, 2004, p.167)
}

Nesse sentido entendemos a preocupação das faculdades incentivando os graduandos a envolver-se nesses estágios visando qualificar cada vez mais na área de atuação, além de colher resultados positivos na educação. Essas práticas oportunizam também novas perspectivas através do desenvolvimento das habilidades e observações que servirão como fonte para um futuro promissor, haja vista que o mercado de trabalho é cada vez mais rigoroso. Apesar de 
tantas ações e ajuda constante de estagiários, muitos desafios ainda são enfrentados pela escola, tais como; falta de recursos, salas superlotadas e ausência de formação continuada. Essas dificuldades permeiam no processo de ensino aprendizagem e tem prejudicado muito a prática docente de maneira geral, sabemos que essas formações contribuem e garantem um melhor desempenho, e deve ser algo permanente na trajetória de qualquer profissional.

Entendemos que ao longo do tempo surgiram mudanças em meio à sociedade que acarretaram uma maior necessidade de buscar novos saberes, que devem ser agregados ao cotidiano e a realidade desses estudantes. Cada profissional da área deve preocupar-se com esse fator para melhor desenvolver suas habilidades, permitindo desenvolvimento e compreensão dos seus educandos. Esse educador deve ter o apoio e o incentivo de todo setor educacional, para que não seja algo obrigatório, mas sobretudo significativo. Esses profissionais devem refletir a cerca de suas didáticas e terem atenção constante, pois sabemos que os estilos mentais são diferenciados nas salas de aula, repensar e fazer uma autoavaliação deve ser fundamental.

Por falta dessas especializações, a modalidade educacional especial tem sido prejudicada, contudo os coordenadores devem intervir, acompanhando, dando total respaldo a esses profissionais, no desenvolvimento de práticas que venham nortear de maneira positiva todo processo pedagógico. Faz se necessário intensificar meios que ajudem na qualidade de ensino. A Constituição Federal dá direito à permanência de todos na escola com igualdade de condições (art. 206. Inc.I) e ter um atendimento educacional especializado, seja dentro da rede regular de ensino ou fora dele como complemento. E segundo a lei de Diretrizes de Diretrizes e Bases da Educação Nacional - LDBN (1996, art.58):

O Atendimento Educacional Especializado será feito em classes, escolas, ou serviços especializados, sempre que, em função das condições específicas dos alunos, não for possível a sua integração nas classes comuns do ensino regular" (BRASIL, LEI N ${ }^{\circ}$ 9394/96, art. 58)

Os alunos com deficiência têm suas limitações, precisam de um ambiente adequado com instrumentos de apoio que auxiliem no sistema de inclusão, que é o ato de incluir sem distinções, integrando a participação do indivíduo em várias dimensões sem sofrer nenhum tipo de dano. Vale comentar que todo ser humano nasce dotados de diferenças, mas para a lei somos regidos pelos mesmos direitos. O artigo 208 da Constituição Federal de forma específica garante que é dever do estado esse tipo de atendimento. Esse direito também é encontrado no 
Estatuto da Criança e do Adolescente - ECA, Lei $\mathrm{n}^{\circ}$ 8.069/90. Diante disso percebemos que muito precisa ser feito nas escolas para abarcar essa demanda, garantindo o acesso a todos sem exclusão.

A Escola Dom Malam abriga uma sala de AEE, para subsidiar nove estudantes com necessidades especiais divididos entre o ensino fundamental I e II, nela são encontrados jogos, cartilhas e vários objetos que são utilizados para ajudar no pedagógico, além do acompanhamento dos registros de atividades dos alunos atendidos. Essa sala recebe outros alunos de outras escolas permitindo ainda menos tempo para integração dos que ali estudam. Percebemos que não existem reuniões com os pais dos alunos com necessidades especiais para refletirem sobre níveis de aprendizagem ou algum outro fator, diante disso podemos afirmar que esse afastamento entre escola e família tem limitado o percurso desses alunos dessa modalidade.

De acordo com as pesquisas realizadas entre os mediadores e os residentes, sobre alguns temas abordados tivemos os seguintes resultados: na visão dos residentes, os docentes precisam progredir muito, especialmente com práticas que incluam realmente esses discentes dentro do planejamento, concluem ainda que esse planejamento deve ser diferenciado dos demais alunos. E quanto ao atendimento educacional especializado e os discentes, consideram bom. No quesito coordenação e reflexo de aprendizagem os resultados foram parecidos com os resultados dos mediadores, precisam melhorar bastante. Isso nos remete a pensar que realmente a escola deve melhorar em alguns setores, para atender esse grupo com mais eficácia, principalmente na questão de acesso desses alunos. Quando falamos de acessibilidade não se remete somente a adaptação dos obstáculos da pedagogia, mas sim as barreiras que impedem as pessoas com deficiência de progredirem e avançarem fisicamente.

A acessibilidade promove meios que aproximam esses estudantes nos ambientes escolares, promovendo também melhor desempenho em todos os quesitos. A pessoa com deficiência física precisa de maiores cuidados, e não podem ser impedidas de circular em outros setores, devem sim, ter acesso a todos os departamentos. Compreendemos que a escola deve construir rampas com corrimão, banheiros, móveis e pisos adaptados para que esses estudantes se sintam mais seguros para percorrerem com mais segurança e autonomia.

925 Id on Line Rev. Mult. Psic. V.13, N. 48 p. 919-933, Dezembro/2019 - ISSN 1981-1179 Edição eletrônica em http://idonline.emnuvens.com.br/id 


\section{Educação Física na Escola Campo}

Muitos acreditam que as aulas de educação física se definem apenas como momentos de diversão nos ambientes escolares, quando na verdade torna-se essencial para o desenvolvimento da criança, principalmente nos anos iniciais aonde a criança está em processo de formação motora. Segundo Kunz (2001) a educação física é identificada como um componente curricular integrado ao projeto pedagógico da escola. Ela deve ser integrada ao planejamento do docente, aliada também as manifestações culturais através de movimentos, danças, jogos, exercícios entre outros. Quando uma escola tem a prática de levar a educação física ao seu alunado conseguimos enxergar a diferença motora em relação a outros discentes que não tiveram as mesmas oportunidades.

Acreditamos que a criança deve liberar as energias, pular e correr. Alguns só tem oportunidade quando são matriculados em algum setor educacional haja vista a correria do dia a dia e devemos lembrar que outros moram em grandes centros urbanos, movimentados, isso torna um fator que pode comprometer essas atividades. Nesse seguimento surge outros agravantes como doenças causadas por falta de exercícios físico, como sedentarismo, que tem prejudicado a população. A criança deve ser incentivada, pois esses movimentos ajudarão a adquirir mais segurança em si próprio. Apesar de tantos benefícios, infelizmente essa escola precisa apresentar mais entusiasmos. Alguns professores apresentam a parte teórica, o contexto cultural linguístico. Eles argumentam ainda, o medo de levar os alunos para quadra de esporte para não ocasionar acidentes. Outro fator que surge é a falta de equipamentos e materiais propícios para esta ação.

Aproveitamos para vivenciarmos nesse local alguns projetos também direcionados pela nossa instituição de ensino voltado para a prática de educação física e educação do campo, dentro da temática inserimos a brincadeira da amarelinha para quebrar a rotina desses alunos, além de criar desafios, possibilitando desenvoltura em diversas áreas como o aumento da força muscular, ritmo corporal, coordenação motora fina, estratégias, controle corporal, equilíbrio, noção de espaço, desenvolvimento da personalidade e desenvolvimento social para o desenvolvimento global do indivíduo, particularmente para a criança em fase de crescimento.

Nas reuniões mensais com toda a coordenação os docentes admitem a importância de trabalhar educação física mesmo em sala de aula com o uso de materiais como bambolês, pula 
corda, bola, jogos e outros, mas são cobrados a intensificar aulas de outras disciplinas como português e matemática. Com isso os dias letivos vão deixando grandes lacunas na vida das crianças. Destaca-se que os demais alunos dessa escola do $6^{\circ}$ ao $9^{\circ}$ ano recebem suas aulas de Educação Física regularmente com jogos, atividades corporais, participação em torneios e jogos escolares. O professor dessa disciplina participa de maneira assídua de todas as atividades, incentivando os jovens e adolescentes a se envolverem. Ao ser entrevistado, falou um pouco sobre essa necessidade de alunos praticarem esses exercícios, não descartando a parte escrita onde estuda a parte cultural que também tem sua importância.

\section{Intervenções e projetos vivenciados na escola campo}

É sabido que a maioria dos alunos não possuem hábito de leitura dentro de seus espaços familiares, consequentemente os educadores encontram muitas dificuldades relativas ao desenvolvimento desses alunos por causa dessa carência. Diante disso vimos a importância de intervir com projetos que despertasse o interesse do alunado pela leitura. Para tanto, foi necessário estudar um pouco mais sobre o assunto para assim desenvolver melhor as atividades. Dentro da escola falava-se bastante em criar esse hábito e as primeiras atitudes tomadas foram disponibilizar livros para os envolvidos. Segundo Villardi (1999, p 11) "Há que se desenvolver o gosto pela leitura, a fim de que possamos formar um leitor para toda vida”. Diante disso compreendemos que as palavras do autor indicam que a escola tem a finalidade de despertar o aluno a ser um leitor assíduo, motivando-o cada vez mais.

Além de contribuir para a formação do sujeito, a leitura proporciona momentos lúdicos de interação, socialização, estimula raciocínio, envolve a criança e ao adolescente em um mundo cheio de aventura e imaginação. Surgiu a oportunidade de participarmos de alguns projetos voltados para essa temática ajudando o estabelecimento de ensino a envolver esses alunos a mergulharem nesse universo tão rico como os contos e as histórias infantis. Em parceria com os professores do $1^{\mathrm{o}}$ ao $5^{\mathrm{o}}$ ano dos anos iniciais, propomos que os mesmos escolhessem um paradidático para ser trabalhado durante uma semana com os educandos de forma diferenciada e atrativa, através de músicas, contos, teatro, danças e etc. Os resultados foram satisfatórios, as turmas foram levadas para o auditório onde ocorreram toda a culminância do projeto, outras turmas puderam apreciar as apresentações. Os residentes participaram 
colaborando com professores durante os ensaios, ornamentação e figurino. Alguns alunos foram levados para outros ambientes para serem ajudados individualmente, crianças que não obedecia a pontuação, com problemas na escrita, outros com dificuldade ainda maior por não saber ler nem escrever

Outra iniciativa surgiu através de um plano de aula desenvolvido na sala do $3^{\circ}$ ano do fundamental, onde esses alunos precisavam de aulas extras de adição e subtração, haja vista que eles precisam dominar essa área exigida pela BNCC. Identificamos que a professora da turma ministrava todos os conteúdos, explicando, tirando dúvidas, sobre tudo orientando, de maneira significante. Apesar disso sempre tem aqueles que necessitam de mais orientação e atenção. Vale ressaltar que as intervenções partiram em conjunto com os professores. Dentro do planejamento colocamos alguns objetos e jogos oferecidos pela biblioteca para diversificar e tornar mais dinâmica e lúdica a aula, pois a matemática torna-se mais fácil quando agregamos outros materiais, algo novo que fuja do mecânico. A aula foi diferenciada, todos os alunos puderam participar. Acreditamos que momentos assim faz-se necessário em todos os estabelecimentos de ensino, entendemos as necessidades individuais e coletivas, desenvolvendo momentos de alteridade e socialização de maneira geral.

Outra medida foi implantada dentro das intervenções com o tema aquecimento global, em parceria com algumas graduandas do curso de Pedagogia. Através desse trabalho conscientizamos a turma a respeito de como cuidar do meio em que vivemos com medidas simples e diária, onde aprendemos a separar o lixo corretamente, além de um breve estudo sobre a coleta seletiva da nossa cidade e os riscos que corremos em meio a uma sociedade que precisa de alerta. Nota-se que medidas como essas oferecidas nos ambientes escolares são de grande importância para o nosso planeta.

\section{Metodologia}

O período da residência pedagógica ocorreu na escola municipal de referência Dom Malan, tendo como procedimentos metodológicos uma pesquisa de campo, bibliográfica, descritiva, participativa, estudo de caso e caderno etnográfico, com abordagem qualitativa e quantitativa. Ter o próprio espaço de residência como campo de estudo, observações, vivências 
e práticas, possibilitou o desenvolvimento eficiente do presente trabalho, haja vista, todos os sujeitos se encontrarem grande parte do tempo no mesmo espaço escolar.

As observações começaram a partir do período de ambientação que teve início em agosto de 2018. Aconteceram algumas entrevistas informais com professores, cuidadores, mediadores e parceiros da escola a fim de coletar ao máximo informações que pudessem fomentar o trabalho e que geraram anotações significativas. O uso do caderno etnográfico foi essencial para ampliar e organizar os dados colhidos. Alguns mediadores e residentes atuantes nessa instituição serviram de instrumento de avaliação. Os mesmos responderam perguntas referentes ao desenvolvimento tanto de alunos quanto do espaço em geral. A partir dos diálogos foram surgindo respostas que fundamentaram diversos pontos aqui abordados.

Os sujeitos da pesquisa responderam questões sobre: a educação especial, acessibilidade, trabalho da coordenação, gestão, inclusão e a relação entre os discentes e o atendimento educacional especializado. A proposta para debate, trazendo outros olhares que também percorreram nesse ambiente durante o trajeto da residência pedagógica. Outros registros se deram através de rodas de conversas com alunos relacionada às práticas de educação física e o desenvolvimento da escola no processo de aprendizagem, os mesmos citaram e consideraram o aprofundamento dos docentes como aspectos fundamentais pra melhorar o ensino. Os projetos vivenciados durante as intervenções foram planejados em parceria com os professores e toda a gestão, utilizando a biblioteca, pátio e sala dos professores para estudo, atividades extras e concretização dos trabalhos.

\section{Resultados e Discussão}

É considerável mencionar que o campo de estágio vem propiciar junto com o programa de residência pedagógica um reconhecimento territorial. Essas realizações nos permitem pensar como os nossos futuros profissionais atuarão dotados de experiências, que serão úteis para o desempenho da prática. As propostas discutidas ao longo do trabalho, garante novas competências e perspectivas. Ao apontar, por exemplo, a questão da acessibilidade, percebemos que nesse contexto a corporação precisa melhorar. Outros resultados que obtivemos foram a respeito do planejamento didático relacionado a pessoa com deficiência nesse espaço. Vale frisar que a participação e contribuição da biblioteca escolar, sempre atuando com muita

929 Id on Line Rev. Mult. Psic. V.13, N. 48 p. 919-933, Dezembro/2019 - ISSN 1981-1179 Edição eletrônica em http://idonline.emnuvens.com.br/id 
precisão, cedendo materiais armazenados ou produzidos por eles mesmos para atender o público. Esse local é considerado uma referência dentro dessa escola por ser um ambiente organizado e agradável.

Outro ponto muito positivo desse campo estar relacionado a alimentação que é sempre elogiada. Nota-se que há uma preocupação da gestão nesse quesito. Destaca-se os dias inseridos na secretaria no início da ambientação onde aprendemos a preencher diários, fazer matrículas, históricos, calcular notas entre outras atividades. Tudo isso permitiu para alguns estagiários através dessas vivências, escolherem a área em que desejam atuar. Houve a necessidade de uma pesquisa mais ampla. Alguns residentes e mediadores atuantes nessa mesma escola tiveram a oportunidade de participar contribuindo também com seu olhar dentro desse contexto. Em relação aos alunos com deficiência e o processo de inclusão dentro da escola, pedimos para destacarem por setores como Bom I; Regular II; Ruim III a relação entre esses alunos e os setores citados.

Tabela 1 - Resultado da entrevista com Mediadores a respeito da relação entre alunos e setores da escola.

\begin{tabular}{|l|c|c|c|c|c|c|}
\hline Participante & Coordenação & Docente & Sala.AEE & Discentes & Acessibilidade & $\begin{array}{c}\text { Reflexos de } \\
\text { aprendizagem }\end{array}$ \\
\hline Mediador A & II & I & II & I & III & III \\
\hline Mediador B & II & II & I & I & III & II \\
\hline Mediador C & II & I & II & II & III & II \\
\hline Mediador D & II & I & I & I & III & III \\
\hline Mediador E & II & II & II & I & III & II \\
\hline
\end{tabular}

Fonte: Autoria própria (2019)

Tabela 2 - Resultado da entrevista com Residentes a respeito da relação entre alunos e setores da escola.

\begin{tabular}{|l|c|c|c|c|c|c|}
\hline Participante & Coordenação & Docente & Sala.AEE & Discentes & Acessibilidade & $\begin{array}{c}\text { Reflexos de } \\
\text { aprendizagem }\end{array}$ \\
\hline Residente A & II & II & I & I & III & II \\
\hline Residente B & II & II & I & I & III & II \\
\hline Residente C & II & II & II & I & III & II \\
\hline Residente D & II & II & II & I & III & II \\
\hline Residente E & II & II & I & I & III & II \\
\hline
\end{tabular}

Fonte: Autoria própria (2019) 
Com os resultados adquiridos dessa pesquisa chegamos à conclusão que para alguns mediadores atuantes, em relação aos professores e alunos, consideram satisfatório, sendo que ainda carece de mudanças. Já em relação aos alunos com deficiência na sala de AEE precisa melhorar um pouco mais para chegar a um melhor nível de aprendizagem. Partindo para coordenação, eles alegam que deve existir projetos e iniciativas voltados a essa modalidade para melhorar o desempenho dos mesmos, respeitando os limites e a individualidade, iniciativas que englobem não apenas o social, mas de maneira geral. Na questão da acessibilidade todos os entrevistados consideraram ruim.

Essa pesquisa tornou-se importante, pois conseguimos incluir dentro dessa perspectiva outros olhares, novas visões, novas opiniões, e detectar alguns problemas existentes, podendo contribuir com sugestões ou medidas de apoio para melhorar ainda mais essa categoria. Para o graduando em Pedagogia, ter a oportunidade de participar do PRP e trazer as vivências do programa para uma pesquisa é mais que gratificante, é poder relatar mais que experiências, é contemplar antecipadamente o seu próprio futuro.

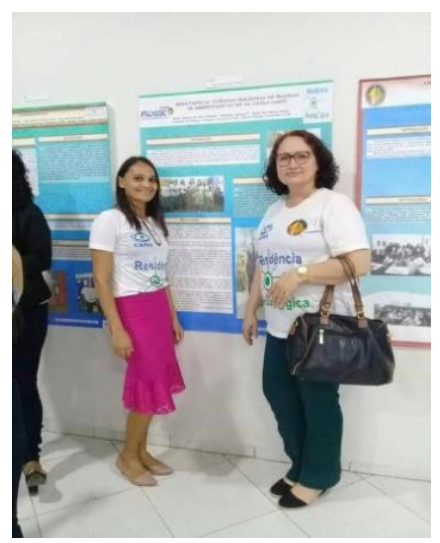

Fonte: Arquivo pessoal - Residente e Preceptora

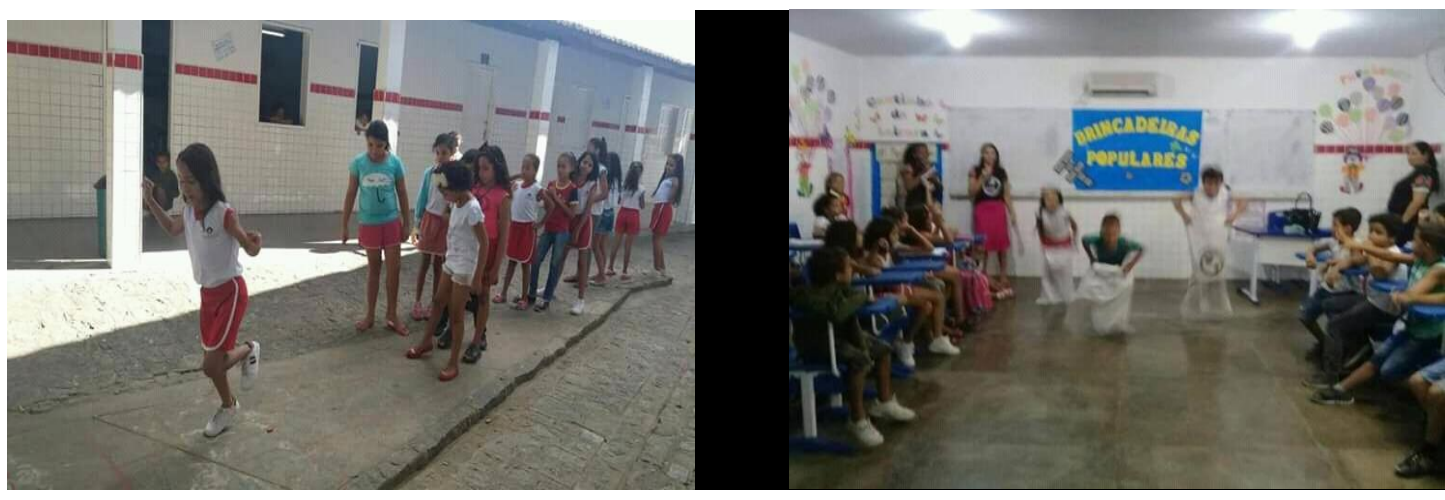

Fonte: Arquivo pessoal - Atividades extraclasse e ludicidade em sala de aula

931 Id on Line Rev. Mult. Psic. V.13, N. 48 p. 919-933, Dezembro/2019 - ISSN 1981-1179 Edição eletrônica em http://idonline.emnuvens.com.br/id 


\section{Conclusões}

Essas experiências adquiridas através do Programa de Residência Pedagógica-PRP oportunizaram vários tipos de conhecimentos, ou seja, o espaço escolar tornou-se útil durante todo o percurso garantindo desempenho e muitas descobertas. Vale destacar que todo desafio vivenciado no estágio supervisionado pode ser comparado há um campo em construção, que junto a programas como este abre caminhos que permite conhecimento, permitindo aos futuros profissionais a compreensão entre teoria e prática, abrindo brechas para métodos e técnicas diferenciadas. Entretanto essas experiências ensinam como sobressair-se em determinadas situações, positiva ou negativa. $\mathrm{O}$ residente aprende a lidar com os desafios existentes nos ambientes educacionais, além de vivenciar as realidades dia após dia.

A residência transforma o acadêmico em um professor pesquisador e reflexivo, através do período de ambientação, período onde exige muita reflexão. As intervenções realizadas na escola campo permitiu entender que o papel do professor se torna muito mais relevante para aprendizagem e a didática apresentada faz toda a diferença para que haja transformação em meio a sociedade. O PRP, programa de residência pedagógica, juntamente com a CAPES e o MEC, trouxeram propostas inovadoras, que possibilitaram mudanças para a trajetória dos graduandos, essas mudanças com certeza terá êxito em todo contexto educacional, pois a parte teórica vista por esses estudantes, possibilitará a junção com as práticas oportunizadas pelo programa. Conclui-se que um bom trabalho da gestão é essencial para um melhor funcionamento de toda escola.

\section{Referências}

BRASIL. Constituição Federal, 1988. Art. 206. Inc.I)

BRASIL. Lei de Diretrizes e Bases da Educação Nacional- LDBN - Lei nº 9394/96, art. 58.

BRASIL. Estatuto da Criança e do Adolescente - ECA, Lei nº 8.069/90.

KUNZ, Elenor. Didática da educação física 2. Ijuí: Ed. Unijuí, 160p. Coleção educação física. (2001)

PIMENTA S. G.; LIMA, M. S. Estágio e docência. São Paulo: Cortez, 2004. 
VILLARDI, Raquel. Ensinando a gostar de ler e formando leitores para a vida inteira. Rio de Janeiro: Qualitymark/Dunya Ed. 1999.

\section{Como citar este artigo (Formato ABNT):}

PEREIRA, Maria Ednalva da Silva; MENEZES, Aurelania Maria de Carvalho; OLIVEIRA, Maria das Graças Bento Gonçalves de. Resultado das Vivências Realizadas no Processo de Ambientação e Imersão do Programa de Residência Pedagógica na Escola Campo . Id on Line Rev.Mult. Psic., Dezembro/2019, vol.13, n.48, p. 919-933 . ISSN: 1981-1179.

Recebido: $02 / 12 / 2019$

Aceito: 05/12/2019 